\title{
Comparative Effectiveness of Clostridial Collagenase Ointment to Medicinal Honey for Treatment of Pressure Ulcers
}

\author{
Adrienne M. Gilligan, ${ }^{1, *}$ Curtis R. Waycaster, ${ }^{2}$ Richard Bizier, \\ Bong-Chul Chu, Marissa J. Carter, and Caroline E. Fife ${ }^{6}$ \\ ${ }^{1}$ Truven Health Analytics, Houston, Texas. \\ ${ }^{2}$ Smith \& Nephew, Fort Worth, Texas. \\ ${ }^{3}$ Truven Health Analytics, Cambridge, Massachusetts. \\ ${ }^{4}$ Truven Health Analytics, Santa Barbara, California. \\ ${ }^{5}$ Strategic Solutions Inc., Cody, Wyoming. \\ EIntellicure, Inc, The Woodlands, Texas.
}

Objective: Compare enzymatic debridement using clostridial collagenase ointment (CCO) with autolytic debridement using medicinal honey in the hospital outpatient setting for treating pressure ulcers (PUs).

Approach: Retrospective deidentified electronic health records from 20072013 were extracted from the U.S. Wound Registry. Propensity score matching followed by multivariable analyses was used to adjust for selection bias and assess treatment effects comparing CCO-treated versus honey-treated PUs. Key outcomes included $100 \%$ granulation and epithelialization at 1 year.

Results: Five hundred seventeen CCO-treated PUs (446 patients) were matched to corresponding honey-treated PUs (341 patients). The majority of PUs were stage III (CCO 56\%, honey 55\%). CCO users had significantly fewer total visits (9.1 vs. $12.6 ; p<0.001)$, fewer total selective sharp debridements $(2.7 \mathrm{vs}$. $4.4 ; p<0.001)$, and fewer PUs receiving negative pressure wound therapy $(29 \%$ vs. $38 \% ; p=0.002$ ) compared with honey.

Innovation: CCO-treated PUs were $38 \%$ more likely to achieve $100 \%$ granulation compared to honey-treated PUs at 1 year, $p=0.018$. Mean days to $100 \%$ granulation were significantly lower for CCO-treated PUs (255 vs. 282 days, $p<0.001)$. CCO-treated PUs were $47 \%(p=0.024)$ more likely to epithelialize at 1 year compared to PUs treated with honey. Mean days to epithelialization were significantly lower for PUs treated with CCO at 1 year (288 vs. 308 days; $p=0.011$.

Conclusion: All stages of PUs treated with CCO achieved faster rates of granulation and subsequent epithelialization compared to PUs treated with medicinal honey as measured by real-world data collected in the hospital outpatient department care setting.

Keywords: pressure ulcer, debridement, granulation, epithelialization, clostridial collagenase ointment, medicinal honey

(c) Adrienne M. Gilligan, et al., 2017; Published by Mary Ann Liebert, Inc. This Open Access article is distributed under the terms of the Creative Commons License (http://creativecommons.org/licenses/by/ 4.0), which permits unrestricted use, distribution, and reproduction in any medium, provided the original work is properly credited.

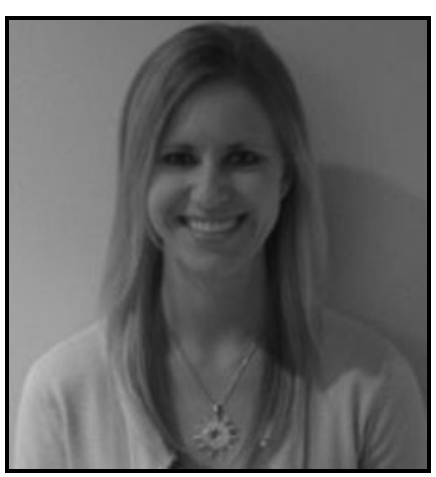

Adrienne M. Gilligan, PhD

Submitted for publication December 7, 2016. Accepted in revised form December 15, 2016.

*Correspondence: Truven Health Analytics, an IBM Company, 2 Riverway \#200, Houston, TX 77056

(e-mail: agilligan@us.ibm.com). 


\section{INTRODUCTION}

PRESSURe UlCERs (PUs) pose substantial clinical and economic challenges to patients, their families, and healthcare providers, annually affecting an estimated 2.5 million patients in the United States (US) at a substantial cost, estimated to range $\$ 9.1-\$ 11.6$ billion annually. ${ }^{1-3}$ Seen most commonly in seriously ill patients, the elderly, and infants due to underlying conditions impairing movement, PUs are an indicator of poor overall health status that may contribute to mortality risk. ${ }^{4,5}$ The prevalence of these high cost adverse events varies considerably by clinical setting, ranging from $0.4 \%$ to $38 \%$ in acute care hospitals, $2.2 \%$ to $23.9 \%$ in long-term care facilities, and $0 \%$ to $17 \%$ in home healthcare settings. ${ }^{6-8}$

Management of PUs is often complicated by the patient's underlying disease and associated pain, infection, and interference with functional recovery leading to lengthened hospital stays and increased costs of care. ${ }^{8,9} \mathrm{PU}$ severity is categorized using a four stage classification system, ranging from stage I (intact skin, nonblanchable erythema) to stage IV (full thickness tissue loss exposing bone, tendon, or muscle). ${ }^{10,11}$ Management requires a multimodal care strategy, including nutritional assessment, body positioning, mobilization, and environmental factors (bedding, chairs, medical devices, etc.), as well as direct treatments to the wound itself. ${ }^{11}$ Treatment of chronic wounds such as PUs entails a systematic approach to preparing the wound bed for healing, consisting of debriding unhealthy and nonviable tissue, controlling exudate and edema, controlling infection and bacterial bioburden, maintaining moisture balance, and promoting healthy granulation tissue. ${ }^{12-17}$

Debridement, the removal of nonviable and poorly healing tissue, foreign material, and bacteria (biofilm) from a wound, is critical to preparing the wound bed for healing and facilitating wound epithelialization. ${ }^{18-21}$ Debridement methods have been described as surgical or sharp, mechanical, chemical, biological, autolytic, and enzymatic. ${ }^{16,22}$ These methods may be used singly or combined serially to optimize the debridement process. Some are considered "selective," acting only on necrotic tissue, or "nonselective" that remove normal, as well as necrotic, tissue. ${ }^{23}$ The choice of debridement method depends on patient factors, wound type, likelihood of infection, available medical expertise, and care setting resources. 9,24

Enzymatic wound debridement with clostridial collagenase ointment (CCO) has been used since the mid-1960s and is the only FDA approved enzymatic agent indicated for debriding chronic dermal ulcers and severely burned areas. ${ }^{25}$ Collagenase, a proteolytic enzyme derived from Clostridium histolyticum, breaks down collagen in necrotic tissue, selectively removing detritus without harming healthy tissue, facilitating granulation tissue formation and epithelialization. ${ }^{22,26-31}$ Other clinical advantages of enzymatic debridement with CCO include ease of application, minimal blood loss, and enhanced tissue proliferation. ${ }^{32}$

Autolytic debridement with support from topically applied medicinal honey is thought to work with the body's natural healing process to cleanse debris and necrotic tissue from the wound. Its activity has been attributed to its acidity increasing oxygen release from hemoglobin, decreasing the activity of destructive proteases, and osmotically drawing fluid from the wound bed to create an outflow of lymph. While there is some evidence supporting the use of honey in wound care, there is however a lack of comparative effectiveness data. ${ }^{33,34}$

\section{CLINICAL PROBLEM ADDRESSED}

There is a lack of current evidence comparing enzymatic debridement with medicinal honeybased autolytic debridement as clinically effective therapies for the management of chronic wounds. The objective of this study was to compare clinical outcomes, particularly granulation and epithelialization, between enzymatic debridement with $\mathrm{CCO}$ and autolytic debridement with support from medicinal honey for the treatment and management of PUs in the hospital outpatient environment. Real-world observational data were used to enable more easily and quickly recruiting a larger patient population that is representative of actual clinical practices to support a better understanding of PU treatment beyond the controlled environment of a clinical trial.

\section{MATERIALS AND METHODS}

\section{Study design}

This study of PU patients used a longitudinal observational case-control confirmatory design approach to compare matched treatment cohorts receiving $\mathrm{CCO}$ (cases) with controls treated with medicinal honey, analyzing the differences and risk factors in achievement of wound granulation and epithelialization over time.

\section{Data source}

Data were drawn from the U.S. Wound Registry (USWR) database, comprising electronic health records (EHRs) from over 100 hospital-based outpatient wound centers in the US and Puerto Rico. 
The USWR is certified to meet the Health Information Technology for Economic and Clinical Health Act (HITECH Act) standards, including adherence to wound care quality measures developed by the USWR as a Qualified Clinical Data Registry (QCDR) and nationally recognized by the Centers for Medicare and Medicaid Services as part of the Physician Quality Report System. ${ }^{35,36}$ Clinical data are collected at the point of care using standardized codes and vocabularies with limited use of free text. ${ }^{37}$ All wound and ulcer types are included, such as diabetic foot ulcers, venous stasis ulcers, PUs, arterial ulcers, surgical wounds, traumatic wounds, vasculitic ulcers, arterial ulcers, sickle cell ulcers, inflammatory ulcers (e.g., pyoderma gangrenosum), and ulcers related to skin disorders such as scleroderma. Ulcers are risk stratified for outcomes reporting using the Wound Healing Index. Interventions include dressings, compression bandaging, off-loading, cellular- and/ or tissue-based therapies, hyperbaric oxygen therapy, negative pressure wound therapy, debridement, and antibiotics. Outcomes measured include healing or wound closure, surgical closure, death, and amputations.

The USWR EHR database was certified to satisfy the conditions set forth in Sections 164.514 (a)-(b)1ii of the Health Insurance Portability and Accountability Act (HIPAA) Privacy Rule regarding the determination and documentation of statistically deidentified data. Woodlands Institutional Review Board, acting as USWR's independent Institutional Review Board, has determined that retrospective analyses of deidentified HIPAAcompliant data described herein are exempt from the requirement of patient consent.

\section{Subject selection}

Patients were selected who had at least one encounter record with a PU diagnosis code (International Classification of Diseases, Ninth Revision, Clinical Modification [ICD-9-CM] diagnosis codes 707.00-707.07, 707.09, and 707.20-707.25) in any diagnosis position between January 1, 2007, and December 31, 2012. The date of the first found PU diagnosis code during this period was the patient's index date. Patients were required to have been treated with either CCO or honey and have at least one more encounter with a PU diagnosis after the index PU event. Subjects were excluded who were treated with both CCO and honey during their follow-up, were younger than 18 years old at index, or whose PUs healed within 2 weeks postindex.

Patients and their wounds were followed from their index date until the earliest of $100 \%$ granu- lation tissue formation, epithelialization, or the end of the study period (December 31, 2012).

\section{Outcome measures}

The primary outcome of interest was complete granulation tissue formation for $100 \%$ of the wound bed, measured as the percentage of the wound bed with granulation tissue formed. Achievement of $100 \%$ granulation (yes/no) and the time to the first recorded encounter noting $100 \%$ granulation were measured. If insufficient data were available for granulation, the percentage of necrotic tissue in the wound was assessed, representing the remaining part of the wound not yet granulated.

The secondary clinical end point of epithelialization was evidence of achieving complete epithelialization (yes/no) and time to complete epithelialization. Wounds were considered epithelialized when all of the following criteria were met: no wound exudate, wound area (length $\times$ width) $<0.2$ square centimeters, and tissue depth $<0.1 \mathrm{~cm}$ or described as "partial thickness," the wound overall was described as controlled or improved and not worsening, and the wound bed was characterized as epithelialized.

\section{Explanatory variables}

The primary explanatory variable was PU treatment with either CCO or honey. Patients were grouped into mutually exclusive comparison cohorts based on receiving PU treatment with either $\mathrm{CCO}$ or honey. The following treatment parameters were calculated using the date of the initial wound care visit and each subsequent wound care visit for PU treatment: number of PUs treated, time to first application (days from index date to the first visit when treatment was applied), days of use (last date of application minus the first date of application), number of treatment episodes (defined by gaps between applications of at least 60 days), visits with treatment (number of visits when treatment was applied), application rate (days of use divided by application count), and percentage of treated visits (application count divided by total visit count).

The following PU characteristics were captured: arrival score for initial visit (ambulatory, cane/ crutches, walker, wheelchair/scooter, and stretcher/bed), number of concurrent wounds, wound age at first visit, wound surface area at first visit, wound depth at first visit, PU stage (unstageable, II, III, or IV), PU location, wound exudate level (none, minimal, moderate, or heavy), periwound characteristics (normal, erythematous, macerated, and other), infection surrogate score ("green event" 
count over treatment time of PU, where "green events" occur when there is an antibiotic order, a laboratory test for bacterial culture, provider's EHR note of infection or oozing green pus from the wound), total visit count, visit frequency (visit count divided by days from first to last visit), total number of selective sharp debridements (visits with Current Procedural Terminology [CPT] codes 97597, 97598, or 11040-11047), debridement rate (debridement count divided by days from first to last visit), and concurrent therapies, including hyperbaric oxygen, negative pressure wound therapy, becaplermin gel, and cellular tissue-derived products (OASIS, Apligraf, Dermagraft, Integra, and PriMatrix).

Other explanatory variables included the following patient demographics and clinical characteristics: age, sex, payer, ethnicity, smoker, receiving palliative care, pain medication, antibiotics, antirejection drugs (immunocompromised), paralyzed, home healthcare, comorbidities (heart failure, coronary heart disease, end-stage renal disease [ESRD], peripheral vascular disease, hypertension, and diabetes).

\section{Analysis}

Wounds receiving $\mathrm{PU}$ treatment with $\mathrm{CCO}$ were matched 1:1 to PUs treated with honey using the following propensity score-based matching approach. The goal of propensity score matching is to reduce bias by statistically emulating the comparator balance inherent in randomized clinical trials (RCTs) so that the distribution of observed baseline demographic and clinical characteristics is similar between treatment groups. ${ }^{38}$ Propensity scores for each wound were modeled using logistic regression with a binary indicator for membership in the CCO or honey PU cohorts as the dependent variable and a vector of the following independent variables at index or first PU visit: patient age, wound age, wound surface area, arrival score, number of concurrent wounds, infection surrogate score, ESRD (yes/no), PU stage, and patient paralyzed (yes/no). CCO-treated PUs (cases) were matched to honey-treated control PUs using the nearest neighbor matching technique, enforcing a caliper of 0.25 times the standard deviation (SD) of the propensity score to maximize the number of available controls (honey-treated PUs) for each CCO-treated PU. ${ }^{39}$ The balance achieved by propensity score matching was assessed using standardized differences comparing the pre- and postmatch distributions of the independent variables included in the propensity score model. ${ }^{38}$

Dependent and independent variables were summarized descriptively, with categorical vari- ables presented as the count and percentage of patients and continuous variables providing the number of observations, the mean, SD, and median. Statistical tests of significance for observed differences between treatment groups were conducted using Chi-square tests for categorical variables and t-tests for continuous variables.

Multivariate models were estimated postmatching to control for any remaining imbalances between cases and controls. Cox proportional hazard models were estimated to identify risk factors for the time from index date to granulation or epithelialization. The assumption of proportional hazards was tested plotting Kaplan-Meier observed survival curves and comparing them with Cox predicted curves from the same variable. Logistic regression models were estimated to examine the impact of patients' demographic, clinical, and treatment characteristics on granulation and epithelialization within a fixed time period (e.g., 1-year follow-up). All models controlled for patients' demographic and clinical characteristics at baseline to estimate hazard and odds ratios (HR and OR) of each factor on granulation and epithelialization.

The threshold of statistical significance for all analyses was set a priori at 0.05 . Statistical analyses were conducted using STATA SE, version 13 (STATA Corp, College Station, TX). Data management and analytic file building were conducted using SAS software, version 9.4 (SAS Institute, Inc., Cary, NC).

\section{RESULTS}

The final matched PU treatment cohorts meeting all selection criteria each included 517 wounds from 446 CCO-treated patients and 341 honeytreated patients found in the USWR from 2007 through 2012 (Table 1).

Patients were on average aged 64 to 66 years with the majority older than 65 years (CCO 59.0\%, honey 52.8\%; Table 2). Around two-thirds of patients were ambulatory on arrival (CCO 66.4\%, honey $63.6 \%$ ), with over half receiving home healthcare (CCO 59.2\%, honey 56.0\%) and over half receiving antibiotics (CCO $57.4 \%$, honey $55.7 \%$ ). The most commonly noted comorbidity was hypertension (both 18\%) followed by coronary heart disease (CCO 13.7\%, honey 7.0\%; $p=0.003$ ) and diabetes (both 11\%). A higher percentage of patients in the honey cohort were prescribed pain medication (CCO 17.0\%, honey 22.6\%; $p=0.052$ ) compared with the CCO cohort (Table 2).

Wound assessment at first visit (Table 3 ) found that the majority of PUs in the matched cohorts 
Table 1. Patient and wound sample attrition applying selection criteria

\begin{tabular}{|c|c|c|c|c|}
\hline \multirow[b]{2}{*}{ Selection Criteria } & \multicolumn{2}{|c|}{ Patients } & \multicolumn{2}{|c|}{ Wounds } \\
\hline & $\mathrm{n}$ & $\%$ & $\mathrm{n}$ & $\%$ \\
\hline PU diagnosis ${ }^{\mathrm{a}}$ found January 1,2007 -December $31,2012^{\mathrm{b}}$ and $\geq 1$ encounter in the USWR after the index date & 9,202 & 100.0 & 20,330 & 100.0 \\
\hline At least 1 application of CCO or medicinal honey & 2,711 & 29.5 & 7,823 & 38.5 \\
\hline At least 18 years old on the index date & 2,685 & 29.2 & 7,752 & 38.1 \\
\hline Not treated with both $\mathrm{CCO}$ and medicinal honey & 2,639 & 28.7 & 4,512 & 22.2 \\
\hline Healed within 2 weeks or had only one visit record in USWR & 2,639 & 28.7 & 4,512 & 22.2 \\
\hline CCO cohort before matching & 2,297 & 25.0 & 3,993 & 19.6 \\
\hline Medicinal honey cohort before matching & 342 & 3.7 & 519 & 2.6 \\
\hline CCO cohort after matching & 446 & 4.8 & 517 & 2.5 \\
\hline Medicinal honey cohort after matching & 341 & 3.7 & 517 & 2.5 \\
\hline
\end{tabular}

aPU diagnosis required one of these ICD-9-CM diagnosis codes: $707.00-707.07,707.09$, or $707.20-707.25$.

${ }^{\mathrm{b}}$ The first found PU diagnosis is the patient's index date.

CCO, clostridial collagenase ointment; PU, pressure ulcer; USWR, U.S. Wound Registry.

had $0 \%$ granulation (CCO 77.2\%, honey 77.0\%) with $>4$ concurrent wounds (CCO $56.7 \%$, honey $51.6 \%)$. Wound age was most commonly $<28$ days (CCO 46.8\%, honey 43.7\%), with mean (SD) wound depth of $0.5(0.8) \mathrm{cm}$, and minimal exudate (CCO $42.7 \%$, honey $46.4 \%$ ). PUs were predominantly at stage III (CCO 56.1\%, honey 55.3\%) with an infection surrogate score of 0 (CCO $40.0 \%$, honey $36.6 \%$ ) and found most commonly in the sacrum or buttock areas.

Honey-treated PUs underwent significantly more selective sharp debridements, with $51.5 \%$ receiving a total of three or more compared with $29.6 \%$ of CCO PUs $(p<0.001)$ and similarly higher mean (SD) numbers of selective sharp debridements (CCO 2.7 [5.2], honey 4.4 [5.8]; $p<0.001$ ), as well as wounds receiving negative pressure wound therapy (CCO 29.0\%, honey 38.3\%; $p=0.002$ ) (Table 4).

Patients were treated (days of use) for a mean (SD) of 34.0 (54.2) days and 33.6 (60.2) days, respectively $(p=0.904)$. Significantly fewer mean

Table 2. Patient demographic and clinical characteristics

\begin{tabular}{lcccc}
\hline $\begin{array}{l}\text { Demographic and } \\
\text { Clinical Characteristics }\end{array}$ & $\begin{array}{c}\text { Clostridial } \\
\text { Collagenase }\end{array}$ & $\begin{array}{c}\text { Medicinal } \\
\text { Honey }\end{array}$ & p & $\begin{array}{c}\text { Standardized } \\
\text { Difference }\end{array}$ \\
\hline No. of patients & 446 & 341 & & \\
Age, mean (SD) & $66.2(20.3)$ & $63.6(20.5)$ & 0.072 & $\mathrm{~N} / \mathrm{A}$ \\
Age group & & & 0.212 & \\
$\quad 18-40$ & $14.1 \%$ & $17.0 \%$ & & 7.96 \\
$\quad 41-64$ & $26.9 \%$ & $30.2 \%$ & & 7.31 \\
$\quad 65+$ & $59.0 \%$ & $52.8 \%$ & & 12.48 \\
Sex & & & 0.469 & \\
$\quad$ Female & $47.8 \%$ & $45.2 \%$ & & \\
$\quad$ Male & $52.2 \%$ & $54.8 \%$ & & \\
Ethnicity & & & 0.027 & \\
$\quad$ Caucasian & $66.4 \%$ & $73.0 \%$ & & \\
$\quad$ African American & $12.1 \%$ & $9.4 \%$ & & \\
$\quad$ Hispanic & $12.3 \%$ & $6.7 \%$ & & \\
$\quad$ Other/Unknown & $9.2 \%$ & $10.9 \%$ & & \\
\hline
\end{tabular}

${ }^{a}$ Used in propensity score matching.

N/A, not applicable; SD, standard deviation.
(SD) total visits were required by CCO-treated PUs (CCO 9.1 [9.9] visits, honey 12.6 [16.6] visits; $p<0.001$, with treatment administered at an average (SD) of $50.6 \%(31.5 \%)$ and $41.8 \%(31.1 \%)$ of visits, respectively ( $p=0.085)$. These observations remained relatively consistent for each of the subsets of patients who achieved $100 \%$ granulation at 1 year and those with epithelialization at 1 year.

\section{Granulation results at 1 year}

A significantly greater percentage of $\mathrm{CCO}$ treated PUs achieved $100 \%$ granulation at 1 year (CCO 42.0\%, honey 35.2\%; $p=0.025$ ) (Table 5). PUs treated with CCO were $38 \%$ more likely to achieve $100 \%$ granulation at 1 year compared to honeytreated PUs based on logistic regression modeling (OR 1.384, 95\% confidence limit [CL] 1.057-1.812, $p=0.018$ ) (Table 6).

The Cox regression found that CCO-treated PUs had a $30 \%$ significantly higher probability of achieving $100 \%$ granulation compared to honeytreated PUs, with a HR of 1.302 (95\% CL 1.0561.605, $p=0.013)$. CCO-treated PUs achieved $100 \%$ granulation within a significantly shorter mean (SD) time frame compared to honey (CCO 255.3 [129.8] days, honey 282.2 [127.4] days; $p<0.001$ ) (Table 5). Figure 1 graphically shows the probability of achieving $100 \%$ granulation during the 1-year follow-up, comparing $\mathrm{CCO}$ and honey cohorts.

\section{Epithelialization results at 1 year}

Logistic regression modeling of epithelialization at 1 year (Table 7) found that CCO-treated PUs were $47 \%$ more likely to epithelialize compared to honey-treated PUs (OR 1.467, 95\% CL 1.051$2.047, p=0.024)$. Significantly higher proportions of PUs treated with CCO achieved epithelialization at 1 year $(28.2 \%$ vs. $21.3 \%, p=0.009)$ (Table 5$)$. 
Table 3. Wound demographic and clinical characteristics

\begin{tabular}{|c|c|c|c|c|}
\hline Wound Characteristics & $\begin{array}{l}\text { Clostridial } \\
\text { Collagenase }\end{array}$ & $\begin{array}{c}\text { Medicinal } \\
\text { Honey }\end{array}$ & $\mathrm{p}$ & $\begin{array}{c}\text { Standardized } \\
\text { Difference }^{\text {a }}\end{array}$ \\
\hline Total wounds & 517 & 517 & & \\
\hline $\begin{array}{l}\text { Granulation \% at first visit, } \\
\text { mean (SD) }\end{array}$ & & & 0.941 & \\
\hline $0 \%$ & $77.2 \%$ & $77.0 \%$ & & \\
\hline $0.1-50 \%$ & $11.6 \%$ & $9.5 \%$ & & \\
\hline$>50 \%$ & $11.3 \%$ & $13.5 \%$ & & \\
\hline No. of concurrent wounds & & & 0.289 & \\
\hline 1 & $18.0 \%$ & $18.2 \%$ & & 0.50 \\
\hline 2 & $11.6 \%$ & $14.9 \%$ & & 9.71 \\
\hline 3 & $13.7 \%$ & $15.3 \%$ & & 4.39 \\
\hline $4+$ & $56.7 \%$ & $51.6 \%$ & & 10.11 \\
\hline Wound age (days) at first visit & & & 0.787 & \\
\hline $0-28$ & $46.8 \%$ & $43.7 \%$ & & 6.22 \\
\hline $28.1-75$ & $22.4 \%$ & $23.8 \%$ & & 3.21 \\
\hline $75.1-182.5$ & $12.8 \%$ & $13.9 \%$ & & 3.41 \\
\hline$>182.5$ & $18.0 \%$ & $18.6 \%$ & & 1.50 \\
\hline $\begin{array}{l}\text { Wound surface area (sqcm) } \\
\text { at first visit }\end{array}$ & & & 0.777 & \\
\hline$\leq 0.5$ & $21.9 \%$ & $20.3 \%$ & & 3.79 \\
\hline $0.6-2.0$ & $21.7 \%$ & $22.1 \%$ & & 0.94 \\
\hline $2.1-10$ & $32.1 \%$ & $31.9 \%$ & & 0.41 \\
\hline$>10$ & $18.2 \%$ & $20.7 \%$ & & 6.36 \\
\hline Missing & $6.2 \%$ & $5.0 \%$ & & 5.05 \\
\hline $\begin{array}{l}\text { Wound depth }(\mathrm{cm}) \text { at first visit }{ }^{\mathrm{b}} \text {, } \\
\text { mean (SD) }\end{array}$ & $0.5(0.8)$ & $0.5(0.8)$ & 0.767 & \\
\hline PU stage & & & 0.989 & \\
\hline Unstageable & $3.3 \%$ & $3.1 \%$ & & 1.10 \\
\hline$\|$ & $13.5 \%$ & $13.9 \%$ & & 1.12 \\
\hline III & $56.1 \%$ & $55.3 \%$ & & 1.56 \\
\hline IV & $27.1 \%$ & $27.7 \%$ & & 1.30 \\
\hline PU location & & & 0.086 & \\
\hline Sacrum/buttock & $32.3 \%$ & $36.6 \%$ & & \\
\hline Other site & $25.7 \%$ & $28.6 \%$ & & \\
\hline Heel & $19.7 \%$ & $15.7 \%$ & & \\
\hline Hip/thigh & $8.5 \%$ & $6.8 \%$ & & \\
\hline Ankle & $7.5 \%$ & $5.0 \%$ & & \\
\hline Back & $6.2 \%$ & $7.4 \%$ & & \\
\hline $\begin{array}{l}\text { Wound exudate level } \\
\text { at first visit }\end{array}$ & & & 0.048 & \\
\hline None & $27.1 \%$ & $20.5 \%$ & & \\
\hline Minimal & $42.7 \%$ & $46.4 \%$ & & \\
\hline Moderate & $26.3 \%$ & $27.1 \%$ & & \\
\hline Heavy & $3.9 \%$ & $6.0 \%$ & & \\
\hline
\end{tabular}

${ }^{a}$ Used in propensity score matching.

${ }^{\mathrm{b}}$ Missing results for $12 \%$ of clostridial collagenase and $16.8 \%$ of medicinal honey cohorts

sqcm, square centimeter.

The Cox regressions found that CCO-treated PUs had a $42 \%$ higher probability of epithelialization at 1 year (HR 1.421, 95\% CL 1.0909-1.8516, $p=0.009$ ). Figure 2 contrasts the probability of $\mathrm{CCO}$ and honey PUs achieving epithelialization during the 1-year follow-up period. The mean (SD) number of days for achieving epithelialization was significantly lower for CCO-treated PUs treated with CCO than those treated with honey at 1 year (288.6 [128.9] days vs. 308.1 [116.6] days, $p=0.011$; Table 5).
Table 4. Treatment characteristics

\begin{tabular}{lccr}
\hline Treatment Characteristic & $\begin{array}{c}\text { Clostridial } \\
\text { Collagenase }\end{array}$ & \multicolumn{1}{c}{$\begin{array}{c}\text { Medicinal } \\
\text { Honey }\end{array}$} & \multicolumn{1}{c}{$p$} \\
\hline All wounds, $n$ (\%) & $517(100)$ & $517(100)$ & \\
$\quad$ Days to first application, mean (SD) & $18.1(65.3)$ & $53.6(143.2)$ & $<0.001$ \\
Days of use, mean (SD) & $34.0(54.2)$ & $33.6(60.2)$ & 0.904 \\
Total visits, mean (SD) & $9.1(9.9)$ & $12.6(16.6)$ & $<0.001$ \\
Treated visits, mean (SD) & $3.3(3.6)$ & $3.1(2.8)$ & 0.201 \\
\% Treated visits, mean (SD) & $50.6(31.5)$ & $41.8(31.1)$ & 0.085 \\
No. of debridements-total & & & $<0.001$ \\
0.0 & $39.7 \%$ & $21.7 \%$ & \\
1.0 & $18.8 \%$ & $13.7 \%$ & \\
2.0 & $12.0 \%$ & $13.3 \%$ & \\
$3.0-4.0$ & $12.2 \%$ & $19.9 \%$ & \\
$\geq 5.0$ & $17.4 \%$ & $31.3 \%$ & \\
No. of debridements per 4 weeks & & & $<0.001$ \\
$<2.0$ & $80.7 \%$ & $67.3 \%$ & \\
$2.0-3.9$ & $14.5 \%$ & $23.6 \%$ & \\
$\geq 4.0$ & $4.8 \%$ & $9.1 \%$ & \\
Concurrent therapies & & & 0.042 \\
$\quad$ Negative pressure wound therapy & $29.0 \%$ & $38.3 \%$ & \\
Hyperbaric oxygen therapy & $2.1 \%$ & $1.2 \%$ & \\
Becaplermin gel or cellular tissue products & $1.4 \%$ & $4.4 \%$ & \\
\hline
\end{tabular}

\section{DISCUSSION}

This comparative analysis of enzymatic debridement with $\mathrm{CCO}$ and autolytic debridement with support from medicinal honey found for the primary outcomes of granulation and epithelialization that CCO-treated wounds were $38 \%$ more likely to achieve $100 \%$ granulation at 1 year and in a significantly shorter time frame (255 vs. 282 days) and $47 \%$ more likely at 1 year to achieve epithelialization also in shorter time frames ( $289 \mathrm{vs}$. 308 days) compared to matched PUs treated with honey. Healthcare resource use was also lower for CCO-treated PUs compared to honey with significantly fewer total visits (9.1 vs. 12.6), fewer total selective sharp debridements (2.7 vs. 4.4 ), and fewer PUs receiving negative pressure wound therapy (29\% vs. $38 \%$ ). These findings of more complete and faster granulation and epithelialization with

Table 5. Observed granulation and epithelialization at 1 year

\begin{tabular}{lccc}
\hline & $\begin{array}{c}\text { Clostridial } \\
\text { Collagenase } \\
\mathrm{n}=517\end{array}$ & $\begin{array}{c}\text { Medicinal } \\
\text { Honey } \\
\mathrm{n}=517\end{array}$ & $\mathrm{p}$ \\
\hline Outcomes & $217(42.0)$ & $182(35.2)$ & 0.025 \\
\hline $100 \%$ Granulation at 1 year, $n(\%)$ & $36.5(20.0)$ & $40.3(18.2)$ & 0.001 \\
$\begin{array}{l}\text { Weeks to 100\% granulation at 1 year, } \\
\text { mean (SD) }\end{array}$ & & & \\
$\begin{array}{l}\text { Days to 100\% granulation at } 1 \text { year, } \\
\text { mean (SD) }\end{array}$ & $255.3(129.8)$ & $282.2(127.4)$ & $<0.001$ \\
$\begin{array}{l}\text { Epithelialization at } 1 \text { year, } n(\%) \\
\text { Weeks to epithelialization at } 1 \text { year, } \\
\text { mean (SD) }\end{array}$ & $146(28.2)$ & $110(21.3)$ & 0.009 \\
$\begin{array}{l}\text { Days to epithelialization at } 1 \text { year, } \\
\text { mean (SD) }\end{array}$ & $288.6(128.9)$ & $44.0(16.7)$ & 0.011 \\
\hline & & & \\
\hline
\end{tabular}


Table 6. Logistic regression for $100 \%$ granulation at 1 year

\begin{tabular}{|c|c|c|c|c|}
\hline PU Treatment Characteristic & $O R$ & $\begin{array}{l}\text { Lower } \\
95 \% \mathrm{Cl}\end{array}$ & $\begin{array}{l}\text { Upper } \\
95 \% \mathrm{Cl}\end{array}$ & p \\
\hline Clostridial collagenase (vs. honey) & 1.384 & 1.057 & 1.812 & 0.018 \\
\hline Patient has home healthcare & 1.934 & 1.463 & 2.557 & $<0.001$ \\
\hline Wound age $>182.5$ days $^{\mathrm{a}}$ & 0.656 & 0.438 & 0.983 & 0.041 \\
\hline Infection surrogate score $3-6^{a}$ & 0.623 & 0.416 & 0.932 & 0.021 \\
\hline Infection surrogate score $2^{\mathrm{a}}$ & 0.517 & 0.325 & 0.824 & 0.005 \\
\hline 2.0-3.9 debridements/4 weeks ${ }^{\mathrm{a}}$ & 0.609 & 0.414 & 0.896 & 0.012 \\
\hline$\geq 4.0$ debridements $/ 4$ weeks $^{\mathrm{a}}$ & 0.265 & 0.125 & 0.563 & 0.001 \\
\hline PU location—heel ${ }^{\mathrm{a}}$ & 0.567 & 0.374 & 0.860 & 0.008 \\
\hline Patient age $80+$ years $^{\mathrm{a}}$ & 0.505 & 0.323 & 0.790 & 0.003 \\
\hline
\end{tabular}

Covariates shown are those significantly $(p \leq 0.05)$ affecting the odds of $100 \%$ granulation.

Reference values: wound age 0-28 days, infection surrogate score 0 , debridements/4 weeks $<2.0$, PU location buttock, patient age 18-40 years.

$\mathrm{Cl}$, confidence interval; $\mathrm{OR}$, odds ratio.

CCO (vs. honey) bear important implications from a clinical perspective, as well as impacts to the economic burden of this costly adverse health condition.

Medical complications that can develop from chronic wound PUs can wreak havoc on patients' health and quality of life. Mechanisms to support faster and more complete PU healing may prevent these sequelae from occurring sooner, providing more days of relief for the patient and their care team.

PUs can impose on the patient, their caregivers, and healthcare professionals a costly cycle of hospitalizations, clinic visits, and home healthcare requiring extensive management resources from a trained multidisciplinary team. In their 2015 study, Woo et al. found the cost of debridement dependent on the resources required over the length of time needed to achieve a clean wound bed, with surgical sharp and enzymatic debridement methods requiring the shortest durations and fewest clinical visits and, thereby, the two most cost-effective debridement methods. Autolytic debridement was said to take the longest to work, relying on the patient's own cellular mechanisms to remove necrotic tissue. ${ }^{17}$

There has been a paucity of comparative studies with medicinal honey, and this study is the first we are aware of comparing enzymatic debridement to autolytic debridement with medicinal honey. A number of studies have compared enzymatic debridement with CCO to other debridement methods, primarily other autolytic modalities, in terms of both treatment efficacy and cost. A US-based, prospective, randomized, parallel-group, openlabel exploratory study of diabetic foot ulcers with 55 participants receiving CCO plus serial sharp debridement compared with supportive care plus serial sharp debridement found that CCO-treated ulcers healed more quickly and completely while costing $\sim \$ 300$ less. ${ }^{40}$ An economic analysis based on a RCT of PU therapy in a long-term care setting found $\mathrm{CCO}$ more cost-effective relative to autolysis with hydrogel dressings. ${ }^{41}$ Muller et al. in an RCT of patients, with grade IV heel pressure sores, found that $91.7 \%$ of the collagenase patients were treated successfully compared with $63.6 \%$ of the patients in the hydrocolloid group $(p<0.005)$ with more rapid closure, further showing collagenase treatment to be more cost-effective than the hydrocolloid treatment owing to the shorter closure time. ${ }^{42}$ An RCT of long-term care facility PU patients comparing $\mathrm{CCO}$ to autolysis demonstrated that at 42 days of therapy $85 \%$ of the CCO-treated patients achieved a clean wound bed without initial

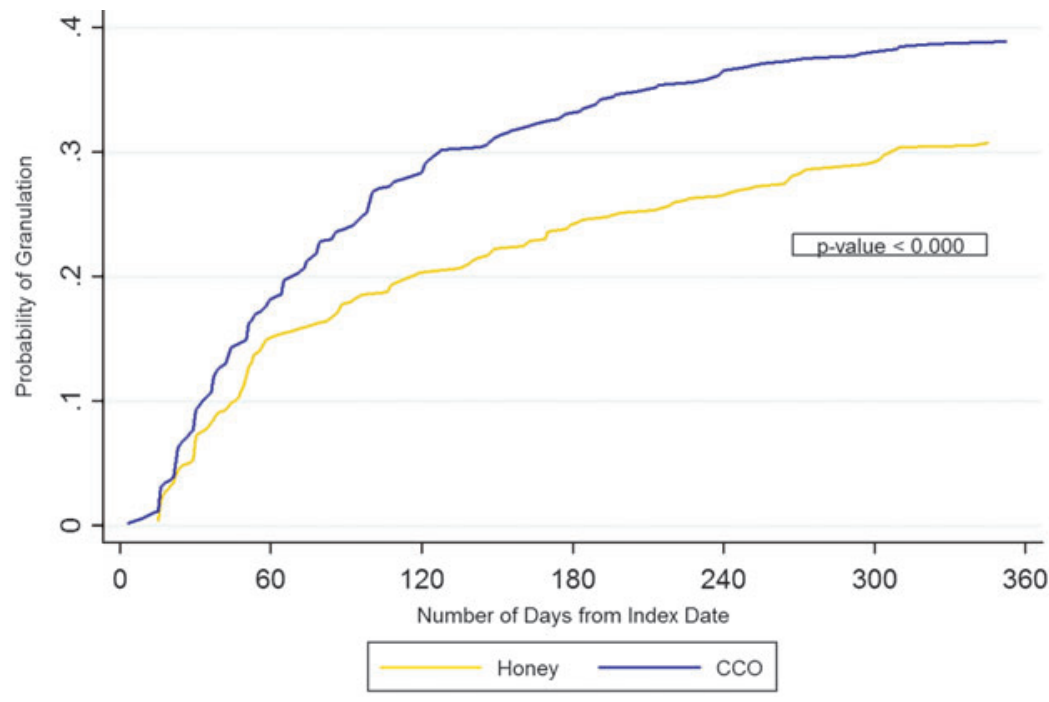

Figure 1. Probability of $100 \%$ granulation over 365 days (Kaplan-Meier curve). 
Table 7. Logistic regression for epithelialization at 1 year

\begin{tabular}{|c|c|c|c|c|}
\hline PU Treatment Characteristic & $O R$ & $\begin{array}{l}\text { Lower } \\
95 \% \mathrm{CL}\end{array}$ & $\begin{array}{l}\text { Upper } \\
95 \% \text { CL }\end{array}$ & $\mathrm{p}$ \\
\hline Clostridial collagenase (vs. honey) & 1.467 & 1.051 & 2.047 & 0.024 \\
\hline 2.0-3.9 visits $/ 4$ weeks $^{\mathrm{a}}$ & 1.547 & 1.025 & 2.335 & 0.038 \\
\hline Patient has home healthcare & 1.422 & 1.005 & 2.014 & 0.047 \\
\hline Male & 0.689 & 0.488 & 0.972 & 0.034 \\
\hline Wound depth $0.1-0.3 \mathrm{~cm}^{\mathrm{a}}$ & 0.620 & 0.407 & 0.946 & 0.027 \\
\hline Wound depth $\geq 0.3 \mathrm{~cm}^{\mathrm{a}}$ & 0.559 & 0.339 & 0.921 & 0.022 \\
\hline Wound age $>182.5$ days & 0.530 & 0.308 & 0.911 & 0.022 \\
\hline Infection surrogate score $2^{\mathrm{a}}$ & 0.524 & 0.303 & 0.937 & 0.029 \\
\hline Infection surrogate score $>6^{a}$ & 0.454 & 0.237 & 0.869 & 0.017 \\
\hline Age $80+$ years $^{\mathrm{a}}$ & 0.493 & 0.270 & 0.899 & 0.021 \\
\hline Wound surface area $>10.0 \mathrm{sqcm}^{\mathrm{a}}$ & 0.471 & 0.258 & 0.861 & 0.014 \\
\hline Ethnicity-other ${ }^{\mathrm{a}}$ & 0.446 & 0.230 & 0.866 & 0.017 \\
\hline$\geq 4$ debridements/4 weeks & 0.417 & 0.176 & 0.988 & 0.047 \\
\hline Patient has paralysis & 0.375 & 0.176 & 0.800 & 0.011 \\
\hline Arrival score $10^{\mathrm{a}}$ & 0.288 & 0.092 & 0.896 & 0.032 \\
\hline
\end{tabular}

Covariates shown are those significantly $(p \leq 0.05)$ affecting the odds of $100 \%$ granulation.

${ }^{a}$ Reference values: visits $/ 4$ weeks $<2$, wound depth $\leq 0.1 \mathrm{~cm}$, wound age 0-28 days, infection surrogate score 0 , patient age 18-40 years, wound surface area $\leq 0.5 \mathrm{sqcm}$, ethnicity white, debridements $/ 4$ weeks $<2.0$, and arrival score 0 .

or concomitant sharp debridement compared with $29 \%$ in the autolysis arm. ${ }^{43}$ In a 1999 study by Mosher of elderly long-term care residents, CCO compared to autolysis, wet-to-dry dressings (mechanical debridement), or fibrinolysin debridement had the highest probability of achieving a clean wound bed, low infection rate, and lowest total cost. ${ }^{44}$ A recent observational, retrospective study compared treatment of stage IV PUs using enzymatic debridement plus selective debridement with selective debridement alone, finding the CCO treatment arm significantly more likely to achieve greater and faster epithelialization 1 and 2 years after treatment initiation with greater wound closure at 1 and 2 years (22\% vs. $11 \%$ after 1 year and $27 \%$ vs. $14 \%$ after 2 years, respectively). ${ }^{32}$ Our results in terms of achieving $100 \%$ granulation and epithelialization at 1 year were similar in both the proportion of patients and the time to closure for CCO in these studies and for honey as an autolytic support method.

This analysis examined outcomes of using enzymatic debridement and autolytic debridement support with medicinal honey. The choice of debridement using any of the available methods depends on the patient's medical condition and the condition of each wound. For each patient, these are unique. The clinician's decision requires consideration of the patient's goals and condition, the wound characteristics, the care setting and the talents of the other care team members, and importantly, evidence of the efficacy and limitations of the various modalities available.

\section{Limitations}

The USWR EHR data used in this study were collected from over 100 contributing hospital outpatient wound care clinics' billing records to support reimbursement and were not collected for research purposes. There may be variability in the data reported among the various contributing clinics. Diagnoses or procedures may be subject to coding error, for which the extent of miscoding or undercoding that could result in bias is unknown, and may also result in measurement error in ICD-9-CM or CPT based variables. Analyses using text fields instead of discrete numeric data may be subject to error resulting from incorrect interpretation of the

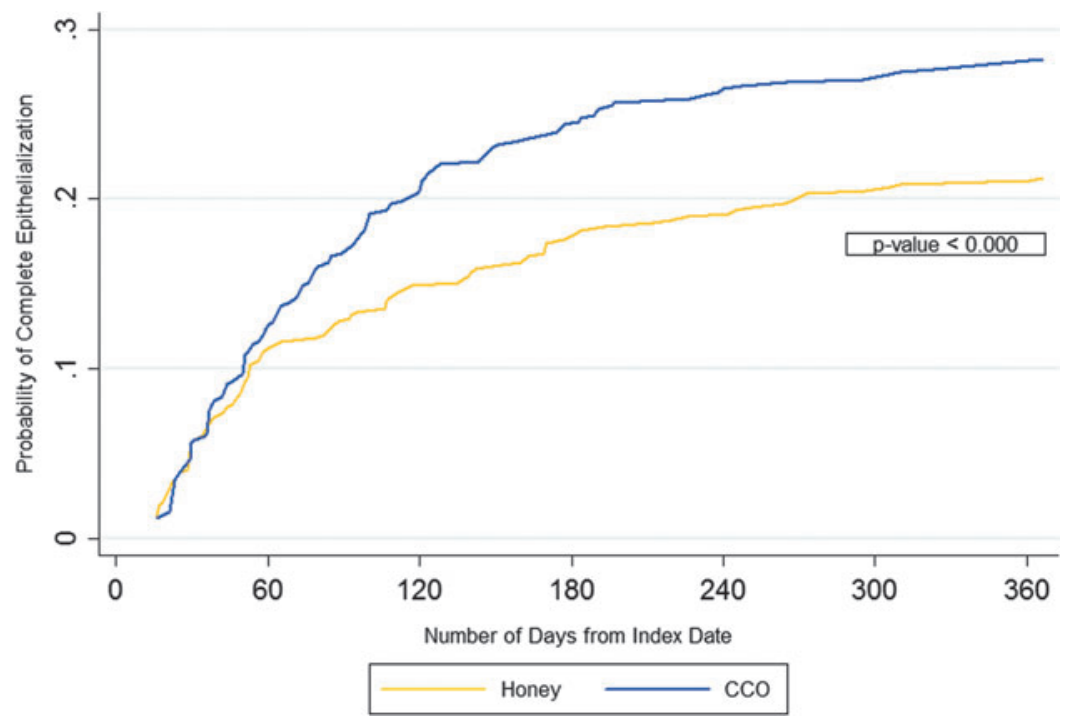

Figure 2. Probability of complete epithelialization over 365 days (Kaplan-Meier curve). 
data. Patient medical history was limited to the patients' visits to a specific provider and clinic, such that patients' outpatient treatment for other comorbidities and by other clinics (e.g., non-USWR clinics) was unknown. Patients with a qualifying PU diagnosis before the study period may have been incorrectly categorized as incident. Multivariate analyses of outcomes provided further adjustment for potentially confounding covariates used in the matching process and an additional degree of robustness in cohort comparisons; however, there is always the potential for unmeasured confounders, especially since information such as comorbidity severity and other sociodemographic variables (e.g., socioeconomic status, basal metabolic index, smoking status, and so on) were unavailable. The USWR EHR is a convenience sample of contributing clinics treating PUs in the US and so findings in this study may not be generalizable to other types of chronic wounds or to patient populations outside of the wound care clinics contributing data to the USWR EHR.

\section{INNOVATION (CONCLUSIONS)}

This is the first retrospective observational study comparing the clinical impact of enzymatic debridement using CCO with autolytic debridement support using medicinal honey for PU management. It found CCO-treated PUs significantly more likely to achieve $100 \%$ granulation and epithelialization at 1 year and at significantly faster rates compared to honey-treated PUs, with fewer healthcare visits, less debridement, and less use of negative pressure wound therapy. Enzymatic debridement with CCO provided statistically significant greater clinical benefit than honey for treating PUs at all PU stage levels. Future research evaluating cost-effectiveness of CCO compared to honey in this population is warranted.

\section{ACKNOWLEDGMENTS AND FUNDING SOURCES}

Editorial/medical writing support for this article was provided by Jay Margolis, PharmD (Truven
Health Analytics). This study was sponsored by Smith \& Nephew, Fort Worth, TX.

\section{AUTHOR DISCLOSURE AND GHOSTWRITING}

A.M.G., R.B., and B.-C.C. are employees of Truven Health Analytics, which was paid by Smith $\&$ Nephew in connection with the development of this article. M.J.C. and C.E.F. were paid consultants to Smith \& Nephew in connection with the development of this article. C.R.W. is an employee of Smith \& Nephew.

\section{ABOUT THE AUTHORS}

Adrienne M. Gilligan, $\mathbf{P h D}$, is a Researcher at Truven Health Analytics. She is also an adjunct assistant professor at the University of North Texas Health Sciences Center College of Pharmacy. Richard Bizier, BS, is a Senior Programmer Analyst at Truven Health Analytics. Bong-Chul Chu, $\mathbf{P h D}$, is a Senior Biostatistician at Truven Health Analytics. Marissa J. Carter, PhD, MA, is the Chief Executive Officer for Strategic Solutions, Inc. Caroline E. Fife, MD, is the Chief Medical Officer at Intellicure, Inc. and the Medical Director, Wound Clinic at St. Luke's Hospital. Curtis R. Waycaster, RPh, PhD, is the Director of Health Economics and Outcomes Research at Smith \& Nephew. He is also an adjunct assistant professor at the University of North Texas Health Sciences Center College of Pharmacy.

\section{REFERENCES}

1. Preventing Pressure Ulcers in Hospitals: Are We Ready for This Change? A toolkit for improving quality of care. Content last reviewed October 2014. Agency for Healthcare Research and Quality, Rockville, MD. www.ahrq.gov/professionals/systems/ hospital/pressureulcertoolkit/putool1.html (last accessed October 28, 2016).

2. Gordon MD, Gottschlich MM, Helvig El, et al. Review of evidence-based practice for the pre- vention of pressure sores in burn patients. J Burn Care Rehabil 2004;25:388-410.

3. Kuhn BA. Balancing the pressure ulcer cost and quality equation. Nurs Econ 1992;10:353-359. 
4. Berlowitz DR, Brandeis GH, Anderson J, Du W Brand $\mathrm{H}$. Effect of pressure ulcers on the survival of long-term care residents. J Gerontol A Biol Sci Med Sci 1997;52A:M106-M110.

5. Thomas DR, Goode PS, Tarquine PH, Allman RM. Hospital-acquired pressure ulcers and risk of death. J Am Geriatr Soc 1996;44:1435-1440.

6. National Pressure Ulcer Advisory Panel Board of Directors. Pressure ulcers in America: prevalence, incidence, and implications for the future: an executive summary of the National Pressure Ulcer Advisory Panel Monograph. Adv Skin Wound Care 2001;14:208-215.

7. Lyder $\mathrm{CH}$. Pressure ulcer prevention and management. JAMA 2003;289:223-226.

8. Graves N, Birrell F, Whitby M. Effect of pressure ulcers on length of hospital stay. Infect Control Hosp Epidemiol 2005;26:293-297.

9. Carter MJ. Cost-effectiveness research in wound care: definitions, approaches, and limitations. Ostomy Wound Manage 2010;56:48-59.

10. National Pressure Ulcer Advisory Panel. NPUAP pressure injury stages. NPUAP 2016 Staging Consensus Conference. www.npuap.org/ resources/educational-and-clinical-resources/npuappressure-injury-stages/ (last accessed October 28, 2016).

11. National Pressure Ulcer Advisory Panel, European Pressure Ulcer Advisory Panel and Pan Pacific Pressure Injury Alliance. Prevention and Treatment of Pressure Ulcers: Quick Reference Guide. Haesler E, ed. Osborne Park, Australia: Cambridge Media, 2014. www.npuap.org/wp-content/ uploads/2014/08/Quick-Reference-Guide-DIGITALNPUAP-EPUAP-PPPIA-Jan2016.pdf (last accessed October 28, 2016).

12. Phillips TJ, Ouahes N. Leg ulcers. Curr Probl Dermatol 1995;7:109-142.

13. Falanga V. Classifications for wound bed preparation and stimulation of chronic wounds. Wound Repair Regen 2000;8:347-352

14. Brem H, Balledux J, Sukkarieh T, Carson P, Falanga $V$. Healing of venous ulcers of long duration with a bilayered living skin substitute: results from a general surgery and dermatology department. Dermatol Surg 2001;27:915-919.

15. Schultz GS, Sibbald RG, Falanga V, et al. Wound bed preparation: a systematic approach to wound management. Wound Repair Regen 2003;11:1-28.

16. Sibbald RG, Woo K, Ayello E. Wound bed preparation: DIM before DIME. Wound Heal S Afr 2008;1:29-34

17. Woo KY, Keast D, Parsons N, Sibbald RG, Mittmann N. The cost of wound debridement: a Canadian perspective. Int Wound J 2015;12:402-407

18. Anderson I. Debridement methods in wound care. Nurs Stand 2006;22:65-72.

19. Steed DL. Debridement. Am J Surg 2004;187: 71S-74S.
20. Steed DL, Donohoe D, Webster MW, Lindsley L. Diabetic ulcer study group. Effect of extensive debridement and treatment on the healing of diabetic foot ulcers. J Am Coll Surg 1996;183:61-64.

21. Levin ME. Pathogenesis and general management of foot lesions in the diabetic patient. In: Bowker $\mathrm{JH}$, Pfeifer MA, eds. Levin and o'Neal's the Diabetic Foot. St. Louis, MO: Mosby, 2001:219-260.

22. Ramundo J, Gray M. Collagenase for enzymatic debridement: a systematic review. J Wound Ostomy Continence Nurs 2009;36(Suppl 6):S4-S11.

23. Beitz JM. Wound debridement: therapeutic options and care considerations. Crit Care Nurs Clin North Am 2012;24:239-253.

24. Moore J, Jensen P. Assessing the role and impact of enzymatic debridement. Podiatry Today 2004;17: 54-61.

25. Collagenase Santyl Ointment. Prescribing Information. Fort Worth, TX: Smith \& Nephew, Inc., 2014

26. Shi L, Carson D. Collagenase santyl ointment: a selective agent for wound debridement. J Wound Ostomy Continence Nurs 2009;36 (6 Suppl):S12S16.

27. Karagol BS, Okumus N, Dursun A, Karadag N Zenciroglu A. Early and successful enzymatic debridement via collagenase application to pinna in a preterm neonate. Pediatr Dermatol 2010;28. 600-601.

28. Shi L, Ramsay S, Ermis R, Carson D. pH in the bacteria-contaminated wound and its impact on clostridium histolyticum collagenase activity: implications for the use of collagenase wound debridement agents. J Wound Ostomy Continence Nurs 2011;38:514-521.

29. Marazzi M, Stefani A, Chiaratti A, Ordanini MN Falcone L, Rapisarda V. Effect of enzymatic debridement with collagenase on acute and chronic hard-to-heal wounds. J Wound Care 2006;15: 222-227.

30. Ramundo J, Gray M. Enzymatic wound debridement. J Wound Ostomy Continence Nurs 2008;35: 273-280

31. Ostlie DJ, Juang D, Aguayo P, et al. Topical silver sulfadiazine vs collagenase ointment for the treatment of partial thickness burns in children: a prospective randomized trial. J Pediatr Surg 2012;47: 1204-1207.

32. Carter MJ, Gilligan AM, Waycaster CR, Fife CE. Treating pressure ulcers with clostridial collagenase ointment: results from the US Wound Registry. Wound Repair Regen 2016;24:904-912.

33. Molan P, Rhodes T. Honey: a biologic wound dressing. Wounds 2015;27:141-151.

34. Molan PC. The evidence and the rationale for the use of honey as a wound dressing. Wound Pract Res 2011:19:204-221.

35. Fife CE, Wall V, Carter MJ, Walker D, Thomson B. Examining the relationship between physician and facility level-of-service coding in outpatient wound centers: results of a multicenter study. Ostomy Wound Manage 2012;58:20-22, 24, 26-28.

36. U.S. Wound Registry. The largest complete patient registry of chronic wound care data in the world. https://www.uswoundregistry.com/index.aspx (last accessed October 12, 2016).

37. Horn SD, Torres A, Jr., Willson D, Dean JM Gassaway J, Smout R. Development of a pediatric age- and disease-specific severity measure. J Pediatr 2002;141:496-503.

38. D'Agostino RB, Jr. Propensity score methods for bias reduction in the comparison of a treatment to a non-randomized control group. Stat Med 1998; 17:2265-2281.

39. Baser 0. Too much ado about propensity score models? Comparing methods of propensity score matching. Value Health 2006;9:377-385.

40. Motley TA, Gilligan AM, Lange DL, Waycaster CR, Dickerson JE. Cost-effectiveness of clostridial collagenase ointment on wound closure in patients with diabetic foot ulcers: economic analysis of results from a multicenter, randomized, openlabel trial. J Foot Ankle Res 2015:8:7.

41. Waycaster C, Milne CT. Economic and clinical benefit of collagenase ointment compared to a hydrogel dressing for pressure ulcer debridement in a long-term care setting. Wounds 2013;25:141-147.

42. Muller E, van Leen MW, Bergemann R. Economic evaluation of collagenase-containing and hydrocolloid dressing in the treatment of pressure ulcers. Pharmacoeconomics 2001;19:1209-1216.

43. Milne CT, Ciccarelli A0, Lassy M. A comparison of collagenase to hydrogel dressings in wound debridement. Wounds 2010; 22:270-274.

44. Mosher BA, Cuddigan J, Thomas DR, Boudreau DM. Outcomes of 4 methods of debridement using a decision analysis methodology. Adv Wound Care 1999;12:81-88.

\section{Abbreviations and Acronyms}

AHRO $=$ Agency for Healthcare Research and Quality

$\mathrm{CCO}=$ clostridial collagenase ointment

$\mathrm{CL}=$ confidence limit

$\mathrm{CPT}=$ current procedural terminology

$\mathrm{EHR}=$ electronic health record

ESRD $=$ end-stage renal disease

HIPAA $=$ Health Insurance Portability and Accountability Act

$\mathrm{HR}=$ hazard ratio

ICD-9-CM = International Classification of Diseases, Ninth Revision, Clinical Modification

$\mathrm{OR}=$ odds ratio

$\mathrm{PU}=$ pressure ulcer

$\mathrm{RCT}=$ randomized clinical tria

$\mathrm{SD}=$ standard deviation

sqcm $=$ square centimeter

USWR $=$ U.S. Wound Registry 